\title{
Oral Cavity Monomorphic Adenoma
}

National Cancer Institute

\section{Source}

National Cancer Institute. Oral Cavity Monomorphic Adenoma. NCI Thesaurus. Code C6845.

A benign epithelial neoplasm arising from the salivary glands in the oral cavity. It is characterized by the presence of a monomorphic cellular infiltrate. 